\title{
Oral health in 6-year-old schoolchildren from Berisso, Argentina: Falling far short of WHO goals
}

\author{
Gabriela Llompart $^{1,2}$, Gustavo H. Marin ${ }^{2,3}$, Martin Silberman ${ }^{2}$, Inés Merlo ${ }^{1,2}$, Oscar Zurriaga ${ }^{4,5}$, GIS (Grupo \\ Interdisciplinario para la Salud) ${ }^{2}$
}

${ }^{1}$ Associate lecturer. Odontology School. La Plata National University. Argentina

${ }^{2}$ Health Department, Buenos Aires Province, Argentina

${ }^{3}$ Associate lecturer. Medical Sciences School. La Plata National University. Argentina

${ }^{4}$ Health Inequalities Area. Centro Superior de Investigación en Salud Pública (CSISP). Generalitat Valenciana. Valencia, Spain

${ }^{5}$ Associate lecturer. Preventive Medicine and Public Health Department. University of Valencia. Valencia, Spain

Correspondence:

Centro Superior de Investigación en Salud Pública.

Avenida de Cataluña, 21.

46020 Valencia, Spain

zurriaga_osc@gva.es

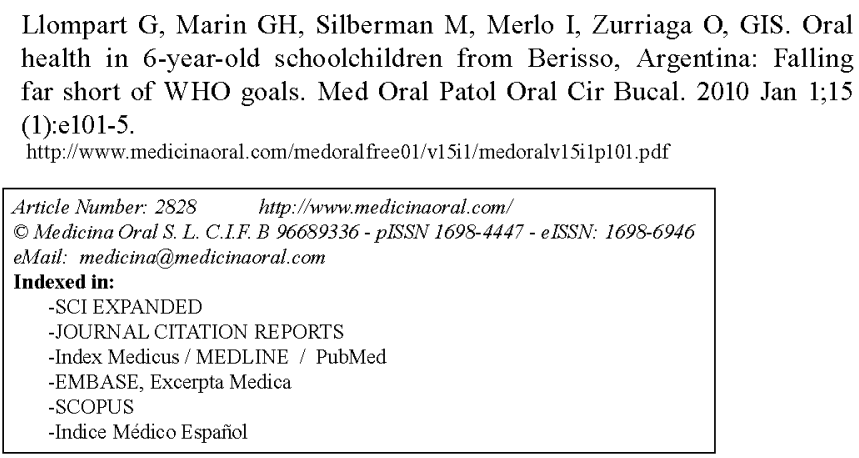

\begin{abstract}
Objectives: Dental diseases in children have been reduced in recent decades in developed countries, although trends remain unclear in other countries. Oral healthcare in Argentina is based on demand and depends on a patient's health insurance coverage. The objective of this study was to determine the oral health situation of the population of six-year-olds in Berisso, Buenos Aires province (Argentina). Study design: A cross-sectional observational study was performed on schoolchildren from public and private schools. The following factors were evaluated: DMFT, DMFS, dft, dfs, significant caries (SiC), filled, decayed and missing teeth, and the prevalence of caries in both primary and permanent teeth. Data was recorded concerning malocclusion, ankylosis, dental fluorosis, DDE index modified, urgent healthcare needs, healthcare system use, orthodontic treatments, filling materials, school type and socioeconomic position. Results: The study was carried out on 804 schoolchildren. The overall prevalence of caries was $70 \%$ (temporary dentition $67.9 \%$, permanent dentition $16.3 \%$ ). The dft index was 4.52 for males and 4.77 for females. For males, dfs index scored 8.78 and for females, it scored 9.27. DMFT index was 0.45 for males and 0.51 for females. DMFS index scored 0.68 for males and 0.80 for females. There were differences between socioeconomic groups (employees and manual workers) in DMFT and DMFS indexes. Of the study population, $\mathbf{5 4 \%}$ had never been seen by a dentist prior to the study. For children who had visited a dentist, $71 \%$ attended state public services. Conclusions: Oral indices in Berisso were worse than in other Argentinean studies and were far from the World Health Organization global goals. There is an urgent need to strengthen the effectiveness of preventive care.
\end{abstract}

Key words: Caries, epidemiology, oral health. 


\section{Introduction}

Oral diseases are both an individual and a community health problem. Oral pathology is a major public health problem because of its prevalence, burden of disease and health impact. Dental diseases have been reduced over the last decades in developed countries (1) but in other countries the trends in mean prevalence and mean dmft among five to six-year-olds are not clear (2) although the common perception is that tooth decay rates are increasing in developing countries. The decline observed in many developed countries has been the result of a number of public health measures, in addition to changing living conditions, lifestyles and improved self-care practices. Health promotion programs are essential (3) to meet the basic health needs of the population, strengthen active outreach to the community, organize primary care, and ensure effective patient referral. Developing and developed countries that offer oral health care within the context of primary health programmes (4) based on proven and effective oral health measures, like Oral Urgent Treatment (OUT), Affordable Fluoride Toothpaste (AFT) and Atraumatic Restorative Treatment (ART), can avoid oral pathology and decrease dental caries, tooth removal and periodontal pathology (5). Oral healthcare in Argentina is basically on demand and depends on a patient's health coverage ("Obra Social" or prepaid).

Adequate knowledge about the oral health situation is the basis for a good oral health promotion program to plan services and preventive activities. Oral health epidemiological surveys are intended (6) to asses oral health needs, identify risk groups, and provide information in order to design policy options and improve the performance of the oral health system.

Epidemiological studies can be used as an incentive to increase community consciousness about oral health and to promote community participation in preventive actions, and to make the reorientation of oral health services towards prevention and oral health promotion easier.

The objective of this study was to determine the oral health situation of the population of six-year-olds in a city of Buenos Aires province (Argentina). The final aim is to establish an oral health baseline prior to introducing promotion and prevention strategies and appropriate health care for specific groups, and to provide the starting point for monitoring the time evolution according to the World Health Organization 2020 global goals for oral health (7).

\section{Material and Methods}

Type of study:

The design was a cross-sectional observational study (prevalence survey).

Population:

The study group was the population of six-year-old children from Berisso (Argentina). Berisso is a city of 95,000 inhabitants in the province of Buenos Aires. The studied population was composed of schoolchildren from public and private schools (zones: La Franja, Villa Nueva, Centro, Barrio Obrero and Los Talas). Children were examined at age six rather than five as this is the age when they begin their first year of Basic General Education (EGB). In Berisso, the proportion of schoolchildren at this age is $98 \%$.

Study variables:

- Sex

Caries: All dental surfaces were examined and the WHO criteria (8) were employed for diagnosis and coding. The following indices were calculated: DMFT, DMFS, dft, $\mathrm{dfs}$, and prevalence of tooth decay in both primary and permanent teeth. The presence of sealants was recorded and the restoration index was also calculated.

Malocclusion: the Angle's classification method was used, considering the presence of cross bite (that can be modified with intercept handling).

Enamel opacities and hypoplasia: the index of development defects of dental enamel (DDE index) modified was used.

Urgent healthcare urgent: emergency references, phlegmon or abscess presence, or serious infection were considered.

Healthcare system use: the previous attendance at a dental clinic (public or private) was recorded.

School ty pe: public or private school.

Socioeconomic position: the father's or mother's occupation was recorded. The Spanish National Occupations Classification was used to code, and for the correspondence between the codes and the social class level based on occupation, we used the Spanish Epidemiological Society method based on the proposal of Domingo and Marcos (9).

Other variables were recorded but not used for this analysis (anchilosis, dental fluorosis, orthodontics treatment).

\section{Examination team:}

Twenty dentists working for the municipality and for the provincial government performed the children's oral exams. They were helped by specially trained auxiliary personnel.

\section{Calibration prior to examination:}

To ensure reliable, valid results, a dentist calibration was done in the days prior to performing the examination. The calibration consisted of activities (theoretical and practical: the criteria was agreement on photography and teeth models) to train the dentists to carry out the examination and to agree on diagnostic and practical criteria. A practical validation was performed in a school with 10 children per examiner. The results were then compared to a reference examination and 22 examiners with the closest scores to the reference were selected. 
Materials and survey conditions:

The clinical examinations took place with artificial light (portable $60 \mathrm{~W}$ lamps) in the spaces assigned for this purpose in the selected schools. The child sat on a chair (neck extended) and the dental examiner sat opposite. A team of two professionals performed the examinations: the dental examiner said the results aloud and the recorder sat alongside and filled in the examination record. Examiners used plain mouth mirrors, Hu-Friedy explorer number 5 and dry field (relative isolation with cotton rolls, blotter triangulated and bulb syringe). Authorization and informed consent was asked of the parents. After the examination, a report was sent to parents and the children with therapeutic needs were referred to an oral health professional in a health centre.

Statistical analysis:

The SPSS ${ }^{\circledR} 11.5$ statistical package was used to compute descriptive statistics (means and proportions, with $95 \%$ confidence intervals). For the inferential statistics, the chi-square test was used to compare proportions.

\section{Results}

804 schoolchildren were studied $(94.9 \%$ of six-year-old schoolchildren in the city of Berisso). Sex distribution was: 394 females (49\%) and 410 males (51\%). The socioeconomic position (according father or mother occupation) distribution was: group I (managers and professionals), 30 (6\%); group II (employees), 148 (29.4\%); group III (manual workers), $266(52.8 \%)$; and group IV (not stated, inadequately described or not classifiable), $60(11.9 \%)$.
The number of children attending public schools was $426(53 \%)$ and for private schools it was 378 (47\%).

The overall prevalence of caries was $70 \%$ for both temporary and permanent dentition. For temporary dentition, the prevalence of tooth decay was $67.9 \%$ and for permanent dentition was $16.3 \%$. For males in permanent dentition, it was $14.8 \%$ and for females $17.8 \%$. In temporary dentition, the prevalence of caries was $67.7 \%$ in males and $68.0 \%$ in females. Sex differences were not statistically significant. The restoration index was $17.6 \%$ for permanent dentition.

Caries indexes are shown in Table 1. The score of the dft index was 4.52 for males and 4.77 for females. For males, the dfs index scored 8.78 and for females 9.27 . The DMFT index was 0.45 for males and 0.51 for females. Finally, the DMFS index scored 0.68 for males and 0.80 for females. None of the indexes have sex differences.

Caries indexes by socioeconomic position (Table 1) worsened from group I (Managers and Professionals) to group III (Manual workers). The differences between group II (Employees) and group III were statistically significant for DMFT and DMFS indexes.

The examination showed the presence of $2851(71 \%)$ of the 1st molars erupted. From them, $3213(80 \%)$ were healthy, $40(1 \%)$ had sealants, $120(3 \%)$ were filled and $642(16 \%)$ had caries.

The most affected by caries were the lower 1st molars, $53.78 \%$ on the right and $46.22 \%$ on the left. The upper 1st molars with caries were 53.86 on the right and 46.32 on the left.

Table 1. Oral health indexes in schoolchildren by sex and socioeconomic position (Berisso, Argentina).

\begin{tabular}{|c|c|c|c|c|c|c|c|c|}
\hline \multirow[t]{2}{*}{ Index } & \multicolumn{2}{|r|}{$\mathrm{dft}$} & \multicolumn{2}{|c|}{$\mathrm{dfs}$} & \multicolumn{2}{|c|}{ DMFT } & \multicolumn{2}{|c|}{ DMFS } \\
\hline & score & $\begin{array}{l}\text { confidence } \\
\text { interval 95\% }\end{array}$ & score & $\begin{array}{l}\text { confidence } \\
\text { interval } \\
95 \%\end{array}$ & score & $\begin{array}{l}\text { confidence } \\
\text { interval } \\
95 \%\end{array}$ & score & $\begin{array}{l}\text { confidence } \\
\text { interval } \\
95 \%\end{array}$ \\
\hline Total subjects & 4.64 & $4.23-5.06$ & 9.02 & $8.20-9.84$ & 0.48 & $0.37-0.58$ & 0.74 & $0.56-0.92$ \\
\hline \multicolumn{9}{|l|}{ Sex } \\
\hline Males & 4.52 & $3.94-5.09$ & 8.78 & $7.67-9.90$ & 0.45 & $0.30-0.59$ & 0.68 & $0.44-0.91$ \\
\hline Females & 4.77 & $4.17-5.37$ & 9.27 & $8.07-10.47$ & 0.51 & $0.35-0.66$ & 0.80 & $0.52-1.09$ \\
\hline \multicolumn{9}{|l|}{$\begin{array}{c}\text { Socioeconomic } \\
\text { position }\end{array}$} \\
\hline $\begin{array}{l}\text { Group I } \\
\text { Managers/ Profes- } \\
\text { sionals }\end{array}$ & 3,53 & $2,06-4,99$ & 6,36 & $3,66-9,06$ & 0,33 & $0,01-0,67$ & 0,53 & $0,14-0,92$ \\
\hline $\begin{array}{l}\text { Group II } \\
\text { Employees }\end{array}$ & 4,12 & $3,37-4,86$ & 7,70 & $6,34-9,06$ & $0,21^{*}$ & $0,08-0,34$ & $0,33^{*}$ & $0,18-0,49$ \\
\hline $\begin{array}{l}\text { Group III } \\
\text { Manual workers }\end{array}$ & 4,94 & $4,36-5,52$ & 9,96 & $8,77-11,15$ & $0,61 *$ & $0,45-0,77$ & $0,99 *$ & $0,67-1,31$ \\
\hline $\begin{array}{l}\text { Group IV } \\
\text { Not classifiable }\end{array}$ & 5,16 & $3,83-6,49$ & 9,45 & $6,91-11,98$ & 0,60 & $0,25-0,94$ & 0,73 & $0,42-1,04$ \\
\hline
\end{tabular}

*DMFT and DMFS differences between Group II and III are statistically significant $(p<0,05)$ 
Hypoplasia cases were $0.19 \%$. The percent of children who needed urgent oral healthcare was $1.19 \%$, basically for pain and infection. Other disorders were detected, like tongue push $(0.19 \%)$, persistent temporary tooth in the front sector and root rest $(<0.15 \%)$.

The bite was normal for $93 \%$ of the cases, but $4 \%$ showed anterior crossbite and 3\% posterior crossbite. $2 \%$ of crossbite cases were on the right side and $1 \%$ on the left side.

With regard to oral healthcare use, 434 children (54\%) had never attended a dentist and $46 \%$ had attended once or more. For children who had attended a dentist, $71 \%$ attended state public services, $27 \%$ private services and $2 \%$ attended both

Oral healthcare use distribution by sex showed $73 \%$ of males and $68 \%$ females attended public services. Visits to private dentists were $25 \%$ for males and $30 \%$ for females.

\section{Discussion}

Although a trend of decreasing caries indexes (prevalence and dft) in five to six- year-old children was reported (10) in several countries in Latin America and the Caribbean between the 1970s and the 1990s, caries prevalence and dft index found in Berisso was higher than in other Argentinean studies performed in the 1980s and 1990s (11-13). This fact is troubling because it implies deterioration compared to an earlier time in similar territories. The scores are even far from the World Health Organization global goals for the year 2000 (14) $(50 \%$ of five to six-year olds will be caries free).

Oral health indexes in Berisso were worsening in children from higher to lower socioeconomic positions, and the differences between employees' children and manual workers' children were statistically significant in caries indexes for permanent dentition. Again, the socioeconomic factors play their role (15) in oral health The scores for Berisso's children were higher for any socioeconomic position than in other Argentinean studies. For example, Battellino et al. (16) found in Cordoba (Argentina) dft indexes from 1.15 (high socioeconomic level) to 3.03 (low socioeconomic level) for kindergarten children, clearly lower than in Berisso.

Notably, despite oral pathology found in the oral examination, more than half the children had never attended a consultation with a professional dentist. It is interesting to assess that the lack of consultation was not related to belonging to public or private schools. Furthermore, it is clear that when there was consultation, this was done mostly in the public sector, from which it could be inferred that it is burdensome to consult the private health system in the dental area. It is necessary to optimize health services to face the still hidden demand.

Thought needs to given regarding the current require- ment for the issuance of an oral health certificate prior to being permitted to enter school, because it is quite likely that there is a lack of compliance or that certificates are being issued without dental inspections having being done.

From the analysis of the first permanent molars arises the need to implement immediate measures to protect the teeth that are healthy and non-erupted, considered potentially healthy $(17,18)$, which constitute the majority group, because in the short time of oral exposure there were a significant number of teeth affected $(19 \%$ including caries and filled).

Anterior crossbite has been the highest incidence. Early detection of these anomalies, initial and simple, can be treated with a simple apparatus by interceptive orthodontics, which prevents these malocclusions evolving and becoming complicated (19).

The results of this study show that there is an urgent need to strengthen the effectiveness of proven preventive actions in order to prevent the further deterioration of oral health. Schools are the natural place to plan and implement health promotion and oral prevention actions. According to these affirmations, since April 2009, national and local authorities have combined their efforts to carry out a health program (20) (Programa Nacional de Salud Escolar - Prosane) that proposes medical examinations, including oral preventive actions, for all pupils attending their first grade (6 years old). Future evaluation of the impact of this program in the oral health of these children may contribute in establishing the efficiency of these measures.

\section{References}

1. Petersson $\mathrm{GH}$, Bratthall D. The caries decline: a review of reviews. Eur J Oral Sci. 1996;104:436-43.

2. Cleaton-Jones P, Fatti P, Bönecker M. Dental caries trends in 5- to 6-year-old and 11- to 13-year-old children in three UNICEF designated regions--Sub Saharan Africa, Middle East and North Africa, Latin America and Caribbean: 1970-2004. Int Dent J. 2006;56:294300 .

3. Petersen PE. The World Oral Health Report 2003: continuous improvement of oral health in the 21 st century--the approach of the WHO Global Oral Health Programme. Community Dent Oral Epidemiol. 2003;31 Suppl 1:3-23.

4. Beiruti N. Views on oral health care strategies. East Mediterr Health J. 2005;11:209-16.

5. Wennhall I, Matsson L, Schröder U, Twetman S. Outcome of an oral health outreach programme for preschool children in a low socioeconomic multicultural area. Int J Paediatr Dent. 2008;18:84-90. 6. Almerich Silla JM, Montiel Company JM. Oral health survey of the child population in the Valencia Region of Spain (2004). Med Oral Patol Oral Cir Bucal. 2006;11:E369-81.

7. Hobdell M, Petersen PE, Clarkson J, Johnson N. Global goals for oral health 2020. Int Dent J. 2003;53:285-8.

8. Oral Health Surveys. Basic Methods. 4 th. ed. Geneva: World Health Organization; 1997.

9. Domingo Salvany A, Marcos Alonso J. Proposal of an indicator of "social class" based on the occupation. Gac Sanit. 1989;3:320-6. 10. Bönecker M, Cleaton-Jones P. Trends in dental caries in Latin American and Caribbean 5-6- and 11-13-year-old children: a systematic review. Community Dent Oral Epidemiol. 2003;31:152-7. 
11. De Muñiz BR. Epidemiologic oral health survey of Argentine children. Community Dent Oral Epidemiol. 1985;13:328-33.

12. De Yankilevich ER, Battellino LJ. Prevalence of dental caries in elementary school children from a metropolitan area of the province of Córdoba, Argentina. Rev Saude Publica. 1992;26:405-13.

13. Yankilevich ER, Cattoni ST, Cornejo LS, Battellino LJ. Dental caries distribution in preschool children in an urban area of Argentina, 1992. Rev Saude Publica. 1993;27:436-44.

14. Global goals for oral health in the year 2000. Fédération Dentaire Internationale. Int Dent J. 1982;32:74-7.

15. Squassi A, Mauro S, Mauro MJ, Sánchez G, Bordoni N. Relationship between oral health in children and poverty related factors. Acta Odontol Latinoam. 2008;21:49-56.

16. Battellino LJ, Cornejo LS, Dorronsoro de Cattoni ST, Luna Maldonado de Yankilevich ER, Calamari SE, Azcura AI, et al. Oral health status evaluation of pre-school children: longitudinal epidemiologic study (1993-1994), Córdoba, Argentina. Rev Saude Publica. 1997:31:272-81.

17. Messer LB. Assessing caries risk in children. Aust Dent J. 2000; $45: 10-6$.
18. Gill DS, Lee RT, Tredwin CJ. Treatment planning for the loss of first permanent molars. Dent Update. 2001;28:304-8.

19. Ngan P, Fields H. Orthodontic diagnosis and treatment planning in the primary dentition. ASDC J Dent Child. 1995;62:25-33.

20. Ministerio de Salud de la Nación homepage on the Internet. Buenos Aires Programa Nacional de Salud Escolar (ProSanE) Creado por Resolución Ministerial 439/2008 cited: 2009 March 21. Available from: http://www.msal.gov.ar/htm/site/noticias_plantilla.asp?Id=1211.

Grupo Interdisciplinario para la Salud:

Matcovick G, Secretti M., Zyromski V, Di Salvi N, Cabrera ML, Cainzo S, Basaldúa L, Savluk V, Mutek C, Drosz S, Cerazari N, Fulco A, Mareco O, Herrera A, Barbonetti C, Paolini J, Redolatti, M, Butler A, Salamendi L, Lutz R, Fernandez J, Navarro M, Garcia E.

\section{Acknowledgement}

This study was partly funded by the Health Regional Authority from Comunitat Valenciana (Spain): Beca BE-06/08 para estancias breves en centros de investigación nacionales y extranjeros (Conselleria de Sanitat. Generalitat Valenciana). 